\title{
Experimental Study of Short-term Training in Social Cognition in Pre-schoolers
}

\author{
Marine Houssa ${ }^{1}$, Nathalie Nader-Grosbois ${ }^{1} \&$ Emilie Jacobs ${ }^{1}$ \\ ${ }^{1}$ Université Catholique de Louvain, Institute of Psychological Sciences, Chair Baron Frère in Special Education, \\ Belgium \\ Correspondence: Marine Houssa, Université Catholique de Louvain, Institute of Psychological Sciences, Chair \\ Baron Frère in Special Education, 10, Place Cardinal Mercier, 1348 Louvain-la-Neuve, Belgium. Tel: \\ 32-10-474-688. E-mail: marine.houssa@uclouvain.be
}

Received: July 15, 2013 Accepted: July 29, 2013 Online Published: October 28, 2013

doi:10.11114/jets.v2i1.181 URL: http://dx.doi.org/10.11114/jets.v2i1.181

\begin{abstract}
Using an experimental approach, our study examined the differentiated effects on pre-schoolers' social cognition of two short-term social information processing (SIP) and Theory of Mind (ToM) training sessions dealing with emotions and beliefs. The links between ToM, SIP, and social adjustment or externalizing behavior were examined. 47 pre-schoolers took part in a pretest session involving cognitive, socio-cognitive and social adjustment measures. The direct socio-cognitive measures involved tasks assessing emotion recognition, ToM emotions, ToM beliefs and social problem-solving. The teachers filled out a personality questionnaire and parents completed the Theory of Mind Inventory, a social adjustment scale and the CBCL. Secondly, they were allocated at random to two experimental groups (ToM training or SIP training) or to a control group. In the experimental groups, each of three children, short training sessions were given using educational materials. Free play was offered in the control group. Finally, all children took part in a post-test session. Our results showed significant improvement in ToM emotions for the ToM training group, in ToM beliefs for the SIP training group, and in social problem-solving for both experimental groups, and some transfer learning. In pretest, significant positive correlations were obtained between social cognition measures and individual characteristics, and between social cognition measures and social adjustment. Significant negative correlations were observed between social adjustment and externalizing behavior, and between social adjustment and emotional reactivity. This study provided some guidelines for formulating a medium-term training program in social cognition aimed at pre-schoolers at risk of displaying externalizing behavior disorders.
\end{abstract}

Keywords: theory of mind, social information processing, training, pre-schoolers

\section{Introduction}

Several theories have been developed regarding the development of social cognition in children, including the Theory of Mind (ToM) model, which uses a developmental-structural approach, and the social information processing (SIP) model, which takes a functional approach. Social cognition abilities develop primarily between 4 and 6 years of age; in this period, children's behavior and thought processes are still flexible (Webster-Stratton, Reid, \& Beauchaine, 2011). In general, strong social cognition abilities are likely to result in adequate social adjustment and allow good interaction (Yeates, Dennis, Rubin, Taylor, Bigler, Gerhardt, \& Vannatta, 2007).

In reference to ToM concepts, pre-schoolers develop the ability to understand their own and other people's mental states, to take other people's perspective, to infer what they know, believe, or feel, and consequently to behave in a well-adjusted way in various social situations (Denham \& Burton, 2003; Deneault \& Ricard, 2013; Denham, Zinsser \& Bailey, 2011; Flavell, 1999; Lane, Wellman, Olson, Labounty \& Kerr, 2011; Wellman, 1991). In other words, children who are good at identifying and understanding other people's emotions should interact successfully and develop harmonious social relationships. Moreover, when children are able to infer and understand knowledge, intentions, and beliefs, they can take other people's cognitive perspective and adjust their own behavior as a consequence. According to this structural-developmental approach, maladjusted children display deficits in social cognition and their coordination of social perspectives. In ToM studies, deficits in at-risk children are postulated in the understanding of mental states, notably of causes and consequences of emotions (Hughes, Dunn \& White, 1998) and of beliefs (Fahie \& Symons, 2003; Walker, 2005). Moreover, 
deficient emotional recognition has also been reported (Blair \& Coles, 2003; Marsh \& Blair, 2008).

In reference to SIP models (Crick \& Dodge, 1994), as they mature, children become more able to think about social problems, and their ability to solve them gradually leads to increasingly efficient social reasoning (Dodge \& Pettit, 2003; Fontaine \& Dodge, 2009). These last authors describe five steps in SIP: encoding of other people's social cues, interpretation of social cues, clarification of goals, response access and response decision. According to this functional approach, maladjusted children display biases during difficult or problem-solving situations: deficits are observed in each of five steps of SIP when they are faced with social interactive situations (Crick et al., 1994; Dodge \& Crick, 1990; Dodge et al., 2003; Fontaine et al., 2009; Mize \& Pettit, 2008). Deficits in social problem-solving are also postulated (Pettit, Dodge \& Brown, 1988).

In summary, deficits in social cognition may lead to the development of externalizing behavior disorders (EB) in children, causing them to be perceived as "hard to manage" (Crick et al., 1994; Runions \& Keating, 2007).

With a view to preventing EB and improving social skills, studies have been conducted to test the efficiency of training in ToM or social problem-solving in pre-schoolers (Melot \& Angeard, 2003) and children with intellectual disabilities (Swettenham, 1996) or with autism (Begeer, Gevers, Clifford, Verhoeve, Kat, Hoddenbach \& Boer, 2011; Feng, Lo, \& Tsai, 2008; Gevers, Clifford, Mager \& Boer, 2006; Hadwin, Baron-Cohen, Howlin, \& Hill, 1996; Ozonoff \& Miller, 1995; Parsons \& Mitchell, 1999; Silver \& Oakes, 2001). Some studies have reported positive effects from this socio-cognitive training. Children's performance in ToM tasks improved after training in understanding emotions (Walker, 2005) and after training in understanding false beliefs in diverse conditions, such as conversations about false beliefs, explanations of correct response, differentiated immediate feedback on their performance or discussion about events in false belief scenarios (Amsterlaw \& Wellman, 2006; Appleton \& Reddy, 1996; Clements, Rustin \& McCallum, 2000; Howlin, Baron-Cohen \& Hadwin, 2011; Kloo \& Perner, 2003).Furthermore, an improvement in SIP was obtained after training in which children talked about concepts arising from stories of peer interaction and did related activities (Bhavnagri \& Samuels, 1996), and after training that included role-playing games, group interaction and puppets (Shure \& Spivack, 1982). SIP training primarily takes the form of medium-term training (e.g., Webster-Stratton, 2000).

Table 1 presents the pre- and post-test measures used by authors who reported some positive effects of ToM or SIP training. Studies involving successful training in social cognition highlight the need for explanations during training in order for learning to occur. Giving children ToM or SIP training has a noticeable impact. This effect has usually been tested with pre-schoolers in several short sessions (up to 12), individually or in groups (of up to 11 children).

In order to better evaluate the impact of these training programs, there is a need for valid assessments of ToM and SIP in pre-schoolers who have limited attention and verbal skills, using visual materials. New methods make this possible, notably ToM emotions and ToM beliefs tasks (Nader-Grosbois \& Thirion-Marissiaux, 2008, 2011a), the ToM task Battery (Hutchins, Prelock, \& Chace, 2008), and the Theory of Mind Inventory questionnaire (ToMI, Hutchins, Prelock, \& Bonazinga, 2010). For SIP abilities, there is the Social Problem Solving Task (RES, Barisnikov, Van Der Linden, \& Hippolyte, 2004), the Social Information Processing Interview (SIP-I, Ziv \& Sorongon, 2011) illustrated by pictures, and the Schultz Test of Emotion Processing - Preliminary Version (STEP-P, Schultz, Ambike, Logie, Bohner, Stapleton, VanderWalde, Min \& Jetkowski, 2010), illustrated by videos.

Table 1. Pre- and post-tests measures from some research in social cognition

\begin{tabular}{ll}
\hline Authors & $\begin{array}{l}\text { Pre/post-test measures } \\
\text { Theory of mind measures }\end{array}$ \\
\cline { 2 - 2 } & Emotions \\
\hline Feng et al., 2008 & $\begin{array}{l}\text { Situation-based scenarios } \\
\text { Emotion recognition cartoons }\end{array}$ \\
\hline & Beliefs \\
\hline Melot et al., 2003 & Appearance-reality \\
& False beliefs \\
Parsons et al., 1999 & False beliefs \\
Howlin et al., 2011 & \\
Kloo et al., 2003 & \\
Ozonoff et al., 1995 & Content task \\
& $\begin{array}{l}\text { Second-order perspective taking } \\
\text { Second-order ToM }\end{array}$ \\
Walker, 2005 & Location change task \\
Appleton et al., 1996 & Misleading container task \\
Clements et al., 2000 & \\
\hline
\end{tabular}




\begin{tabular}{ll}
\hline & Emotions and beliefs \\
\hline $\begin{array}{l}\text { Hadwin et al., 1996 } \\
\text { Bevers et al., 2006 }\end{array}$ & $\begin{array}{l}\text { Understanding of belief and emotion concepts } \\
\text { ToM test (Muris et al., 1999) } \\
\text { Amsterlaw et al., 2006 }\end{array}$ \\
& $\begin{array}{l}\text { Location change task } \\
\text { Content task } \\
\end{array}$ \\
& $\begin{array}{l}\text { Seeing-knowing task } \\
\text { Appearance-reality task }\end{array}$ \\
& False belief emotion task \\
\hline & Social information processing measures \\
\hline Bhavnagri et al., 1996 & Problematic peer-related situations \\
Shure et al., 1982 & Problem-solving test (PIPS, Shure et al., 1974) \\
Webster-Stratton, 2000 & Wally problem solving (Webster-Stratton, 1990) \\
\hline
\end{tabular}

\section{Objectives}

Firstly, this study aims to test whether performance in social cognition tasks can be improved by means of short stimulations; that is, to assess the differentiated effects of two types of experimental training on the level of social cognition skills in pre-schoolers. No study has ever combined structural-developmental and functional approaches in order to investigate the respective impacts of one-shot ToM training and of one-shot SIP training on ToM and SIP abilities, taking potential transfer learning into consideration. We predicted that (1a) children who received ToM training would have significantly better performance in ToM post-test measures compared with their pretest abilities, and that (1b) children who received SIP training would have significantly better post-test performance in SIP measures compared with their pretest abilities. As regards the potential transfer effect, we predicted that children who received ToM training would improve their SIP abilities in post-test and children who benefited from SIP training would improve their ToM abilities in post-test (1c).

The second objective was, with reference to a heuristic model of social skills (Nader-Grosbois, 2011a), to explore the links between ToM, SIP abilities and adults' perception of children's social adjustment and externalizing behavior in the pretest session, taking into account individual characteristics (developmental age, personality). We hypothesized positive links between ToM and SIP abilities and developmental age (2a) and specific factors of personality (2b), as well as between social cognition and social adjustment (2c); however, we predicted negative links between ToM and SIP abilities and externalizing behavior (2d), and the 'emotionally reactive' score (2e).

\section{Method}

\subsection{Participants}

The participants were 47 children ( 23 boys and 24 girls), aged between 3 years 9 months and 5 years 6 months $(M=4.7$ years, $\mathrm{SD}=4.9)$. They were recruited in Belgian French-speaking schools. The teachers identified children who met the inclusion criterion of elementary comprehension and production of spoken French. The exclusion criteria were developmental delay, intellectual disabilities or behavioral disorders.

\subsection{Instruments}

\subsubsection{Differential Scales of Intellectual Efficiency - Revised (EDEI-R, Perron-Borelli, 1996).}

These scales were used in the pretest session to check that children had verbal and non-verbal developmental ages between 3 years 6 months and 5 years 6 months, in order to be included in the sample.The verbal developmental age was obtained by means of scores in two scales: "knowledge" and "social understanding", and the non-verbal developmental age by means of "practical adaptation". As regards the validation, the correlations calculated between the raw scores of all scales were high: they varied between .47 and .88 ; half of the scores were .70 or below.

\subsubsection{ToM Emotions Tasks (Nader-Grosbois \& Thirion-Marissiaux, 2011a).}

(1) Preliminary task of facial emotional expression (FEE) recognition. The four basic emotions (joy, sadness, anger, and fear) were illustrated by pictures and had to be recognized by the child.

(2) Causes of emotions task. This task involved four scripts all beginning "Three friends go on a picnic in the forest", with two illustrations. Each script (with a third picture) ended differently, to elicit an appropriate response according its emotional quality: joy (friends eat picnic); sadness (picnic canceled because of rain); fear (threatening dog is approaching the picnic); or anger (picnic is ruined by two friends). For each script, the experimenter first read out the script (the protagonist's face was left blank), and the participant was then asked to assign an emotion to the protagonist by pointing to the most appropriate of the four FEE. The response to each 
script was scored between 0 and 1.5 points according to the participant's justification $(0=$ false FEE, no or incoherent justification; 0.5 = false FEE, coherent justification; 1 = correct FEE, no or incoherent justification; $1.5=$ correct FEE, coherent justification). The maximum score was 6 points.

(3) Consequences of emotions task. Four scripts were illustrated by two pictures, presenting: joy (receiving a gift); sadness (pet's death); fear (imagining monsters in bedroom at night); and anger (conflict between friends). The experimenter explained the beginning of the script (two pictures). Then, the child was asked to infer the protagonist's behavior and to finish the script by choosing one of three pictures corresponding to socially adjusted behavior, socially maladjusted behavior or neutral behavior. The child justified the choice. The response to each script was scored between 0 and 1.5 points according to the participant's justification $(0=$ socially maladjusted or neutral behavior, non-justified or incoherent justification; $0.5=$ socially maladjusted or neutral behavior, coherent justification; 1 = socially adjusted behavior, non-justified or incoherent justification; $1.5=$ socially adjusted behavior, coherent justification). The maximum score was 6 points. The two ToM emotions tasks were scored out of a combined total of 12 points.

A recently created computer version of these tasks was used in this study. The factor analysis revealed two subscales (causes and consequences) which were found in the original version. Cronbach's alpha was .57, and the test-retest stability was highly significant for the two subscales (between .56 and .68).

\subsubsection{ToM Beliefs Tasks (Nader-Grosbois \& Thirion-Marissiaux, 2011a).}

These five tasks estimated the understanding of beliefs.

(1) Deception skills test (Oswald \& Ollendick, 1989). The experimenter hid an object in one hand, and the child then did likewise. The experimenter noted whether or not the child really hid the object.

(2) Change of representation task (Flavell, Everett, Croft \& Flavell, 1981). The experimenter was sitting opposite the child with a picture of a turtle placed between them, and the child was asked: "What do you see?" and "What do I see?"

(3) Appearance-Reality task (Flavell, 1986). Three substitute objects were presented: (a) a flashlight in the shape of a mobile phone, (b) an eraser in the shape of a peanut in its shell and (c) a telescope looking like a glue stick. The child was asked two questions: "If you look at this object and you don't touch it, what does it look like?" and "What is it really?"

(4) Unexpected content task (Perner, Leekam \& Wimmer, 1987). The child was shown a Smarties box and the experimenter asked: "What is inside the box?" The child then opened the box and found pencils. The pencils were returned to the box and the child was asked: "What did you think was in the box before it was opened?" and "What will your mother think is in the box if she has not seen inside it?"

(5) Change of location task (Wimmer \& Perner, 1983). This corresponds to the "Max and the transfer of chocolate" task.

These ToM beliefs tasks were scored out of a total of 5 points ( 1 point for each task).

For the validation, the inter-judge agreement was very high (agreement percentage between $99 \%$ and $100 \%$; Cohen's kappa between .98 and .99; Pearson correlation coefficient between .99 and 1). No difference between the test and retest session was observed.

3.2.4 Social Problem-solving Task (RES, Barisnikov et al., 2004).

This task assesses children's capacity to judge whether or not other people's social behavior is appropriate and the extent to which their judgment refers to conventional and moral rules. Participants were shown 14 items illustrated by 14 pictures in which a character displayed appropriate or inappropriate social behavior in everyday social situations. Three questions were asked. (1) "What is happening in the picture? What do you think? Is he/she doing something that is good or not good?" (identification of socially adjusted or maladjusted behaviour, maximum score =2); (2) "Can you show me what is good/not good?" (identification of the target behavior, maximum score = 1). (3) "Why is it good/not good?" (justification, maximum score =7). The maximum score for all items is 140 .

The inter-judge agreement was 98\% (Hippolyte, Iglesias, Van der Linden \& Barisnikov, 2010).

3.2.5 Theory of Mind Inventory - French version (ToMI, Hutchins et al., 2010; translated by Houssa, Mazzone $\&$ Nader-Grosbois, in press).

This questionnaire measures caregivers' perception of children's ToM abilities. It presents 39 statements (e.g., "My child understands that people can lie to purposely mislead others"). Caregivers indicated their degree of agreement with each statement by placing a vertical mark along a continuum ranging from "definitely not" to "definitely." The score for each item ranged from 0 to 20. 
The validation of the French version matched the original version. Cronbach's alpha was .94, and the coefficient of test-retest stability was very significant $(r=.86)$ (Houssa et al., submitted).

\subsubsection{Child Behavior Checklist (CBCL, Achenbach \& Rescorla, 2000).}

The CBCL includes items to assess behavioral and emotional problems in children. This measure generates two factors: externalizing and internalizing behaviors. In this study, we used the externalizing behavior score (EB),corresponding to the sum of scores in the subscales "Aggressive behavior" (19 items) and "Attention problems"(5 items).We also used the subscale for "Emotional reactiveness" (ER), which is an internalizing behavior. Caregivers had to report on a Likert scale whether the behavior was never, sometimes, or often/always observed. The higher the score, the higher the level of EB or ER.

The scales had Cronbach's alphas of between .63 and .86 and a test-retest reliability of .85 .

3.2.7 Bipolar Rating Scales based on the Five Factor Model (EBMCF, Roskam, De Maere-Gaudissart \& Vandenplas-Holper, 2000).

This questionnaire measures the child's personality in reference to five factors (extraversion, agreeableness, conscientiousness, emotional stability, and openness). The 25 items are completed by caregivers (or teachers), by choosing between two opposite adjectives on a Likert scale.

The validation was carried out with 321 children. The factor analysis confirmed the 5 factors, with Cronbach's alphas of between .70 and .93 . The coefficients of test-retest stability were highly significant (between .66 and .93 for teachers, between .80 and .89 for caregivers).

\subsubsection{Social Adjustment Scales (EASE, Hughes \& Soares-Boucaud, 1997)}

This measures adults' perception of children's socio-emotional adjustment. It includes items relating to social skills (non-ToM) and items dealing with perspective-taking abilities (ToM). It was completed by caregivers and/or teachers. For each item, they had to indicate whether the behavior was non-existent or rare (0), frequent (1) or usual (2).

The validation was carried out on 327 pre-schoolers. The two subscales had good internal consistency (Cronbach's alpha was .77 for the ToM scale and .79 for the non-ToM scale). Authors have found a significant regression between the "ToM scale" and verbal developmental age $(r=.22)$ (Comte-Gervais, Giron, Soares-Boucaud, \& Poussin, 2008).

\section{Procedure}

Information letters and a consent form for the child's participation were given to parents via their teachers. Participants were tested in a quiet room at school or at the Institute of Psychological Sciences. In the pretest session, four tests were administered individually in two sessions of 45 minutes: EDEI-R scales, ToM emotions and beliefs tasks and the RES. Then, children were randomly assigned to one of the experimental groups (ToM or SIP groups) or to the control group. They participated in a training or free play session for 45 minutes and finally, they were assessed in a posttest session for 45 minutes, by means of ToM emotions and beliefs tasks and RES (see Figure 1). There was an interval of 1-4 days between pre- and post-tests.

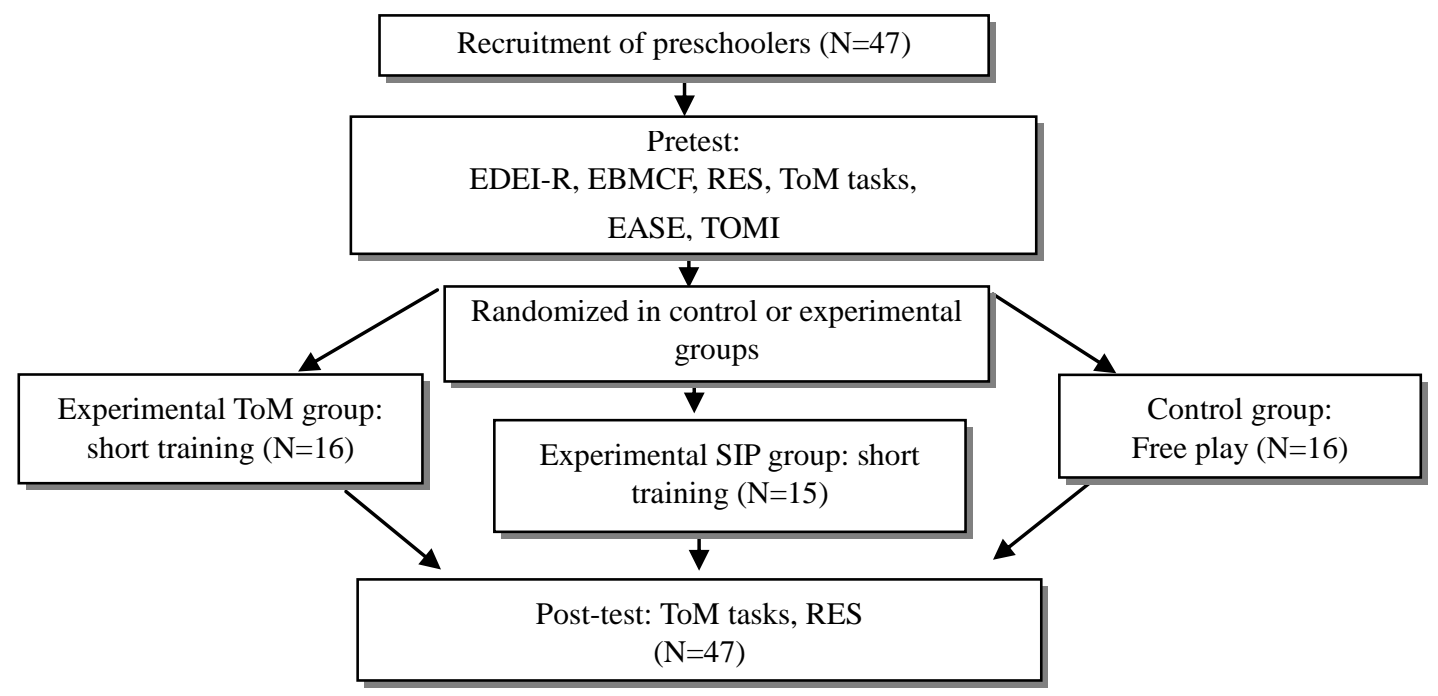

Figure 1. Design 


\subsection{Training in Experimental Groups}

In the experimental groups, children received brief stimulation involving one of the forms of training, in a quiet room. They were trained in subgroups of three, as this allowed them to help one another complete or correct their answers, which could result in socio-cognitive conflict helping their thoughts. Furthermore, there was a speaking slot, which ensured that each child had speaking time.

Open-ended questions were asked about the presented situations in order to prompt discussion, and feedback was provided after each response, as well as an explanation of the correct or expected response. Correct answers were given positive feedback and incorrect responses were corrected with an explanation (differentiated immediate feedback on the performance in the task). The experimenter also reminded the participant of the general principle related to the task (such as the social rules that could be applied in this social situation); that is for the generalization of the knowledge. Training was carried out by a female experimenter. Finally, in both training sessions, different types of materials were used - evidence-based resources and educational materials - as well as different styles of resources ("unanimated" and "animated").

Table 2 summarizes the training in social cognition in reference to ToM and SIP models. Appendixes A and B detail, for ToM training and SIP training respectively, the type of resources, the functions in which training was given (mental states or social situations), the presented situations, and the timing.

Table 2. Training in social cognition in reference to ToM and SIP models

\begin{tabular}{|c|c|c|}
\hline & \multicolumn{2}{|c|}{ Types of training } \\
\hline & Theory of Mind & Social Information Processing \\
\hline $\begin{array}{l}\text { Theoretical } \\
\text { background }\end{array}$ & Howlin et al., 2011 & Dodge et al., 1990 \\
\hline Functions & $\begin{array}{l}\text {-Beliefs and false beliefs } \\
\text {-Recognition of emotions } \\
\text {-Causes and consequences of emotions }\end{array}$ & $\begin{array}{l}\text {-Each of the five SIP steps } \\
\text {-Social problem-solving }\end{array}$ \\
\hline Stimulated skills & $\begin{array}{l}\text {-Inferring mental states (beliefs, emotions) } \\
\text {-Understanding other people's perspectives } \\
\text {-Talking about emotions, causes, and consequences } \\
\text { in positive and negative social situations } \\
\text {-Identifying social emotions }\end{array}$ & $\begin{array}{l}\text {-Emotion and provocation cue interpretation } \\
\text {-Response access } \\
\text {-Decisions about instrumental and social goals } \\
\text {-Generating alternative solutions in relation to critical } \\
\text { social situations }\end{array}$ \\
\hline $\begin{array}{l}\text { Evidence-based } \\
\text { resource }\end{array}$ & Pictures of emotions (Howlin et al., 2011) & $\begin{array}{l}\text { Critical social situations: } \\
\text { - Schultz Test of Emotion Processing - Preliminary } \\
\text { version (STEP-P, Schultz et al., 2010): scenarios } \\
\text { illustrated by short videos } \\
\text { - Social Information Processing - Interview(SIPI-P, } \\
\text { Ziv et al., 2011): scenarios illustrated by pictures }\end{array}$ \\
\hline $\begin{array}{l}\text { Educational } \\
\text { material }\end{array}$ & $\begin{array}{l}\text {-Mental Simil (Juarez Monfort et al., 2009): } \\
\text { illustrations of false beliefs } \\
\text {-Cartoon extracts }\end{array}$ & -Pictures about emotions \\
\hline
\end{tabular}

\subsubsection{ToM Training Experimental Group}

The goal was to stimulate the comprehension of emotions and of beliefs, based on the program conceived by Howlin et al. (2011), who described five developmental levels of these abilities. As detailed in Table 2, we stimulated children to infer mental states in the protagonist, to talk about his or her emotions and beliefs etc. The progression of this training reflects the five levels.

Before the session, each child received an envelope with 4 pictures of faces representing the expression of the four basic emotions. We asked the children to show the sad face, then the happy face etc. Correct recognition was a necessary condition in order to begin the training.

The first part used the pictures and program design of Howlin et al. (2011). Children had to say or point to the protagonist's emotion, and at the end of each story they had to reply to some questions about the protagonist's emotions, desires and beliefs and to justify their choice. If the child gave a correct reply, the experimenter reinforced and consolidated this reply. By contrast, if the reply was incorrect, then the experimenter gave the correct reply and the reason.

The second part comprised the presentation of cartoon extracts (e.g., Snow White) where the protagonist was in a situation eliciting the emotions of joy, fear, sadness, anger, or had a false belief. The purpose was to train the participants to understand causes and consequences of emotions and some aspects of ToM beliefs, such as 
reporting another person's false belief.

The third part featured the game "Mental Simil" (Juarez Monfort, Sanchez, \& Monfort, 2009) presenting a series of pictures illustrating stories featuring false beliefs. The experimenter showed pictures one by one and told the story. The children had to explain and talk about the featured false beliefs.

\subsubsection{SIP Training Experimental Group}

As explained in Table 2, the SIP training used two sets of materials: video-based SIP illustrating social situations from the "Schultz Test of Emotion Processing-Preliminary Version" (STEP-P, Schultz et al., 2010) and stories illustrating social situations with bears from the "Social Information Processing Interview for Pre-schoolers" (SIPI-P, Ziv et al., 2011).

The STEP-P includes three aspects of the SIP model: "emotions", "provocation", and "goal acquisition". The emotions category contains videos that present scenarios in which either an emotion-eliciting event occurs or a child displays emotion-related behavior. The provocation category contains videos that present scenarios in which a child receives provocation of ambiguous intent. The goal acquisition category contains 20 videos that present scenarios in which children attempt to attain a goal (Schultz et al., 2010). Each child in the SIP group watched 3 videos from each category. At the end of each video, the experimenter questioned the child to check if he/she understood what had happened and asked if he/she could explain what had occurred. Then, the child tried to identify the emotion felt by each protagonist, indicate if one of them acted expressly, and predict the verbal and non-verbal behavior of the protagonists. Finally, the experimenter asked each child to "take the place of the protagonist" and asked if they had had a similar experience themselves, and how they reacted/would have reacted in this situation, as a way of generalizing the concepts involved.

In addition two stories from the SIPI-P illustrating critical social situations with teddy bears were presented to children. The experimenter told the story and asked the children questions about it. Each child answered the questions, which were a way of checking the child's comprehension of the facts. Children had to judge a protagonist's potential reactions as well-adjusted or maladjusted. The experimenter asked the children to say if they had had a similar experience themselves, to talk about emotions felt in the past, and to consider what could be done to manage them.

\subsection{Control Group}

Control children participated in a play session in groups of 3 for 45 minutes. Children played a snakes and ladders game. The experimenter was the same as for the experimental groups.

\section{Results}

\subsection{Pretest and Post-test Performance}

Table 3 presents the means and standard deviations for all variables in the pretest session.

Table 3. Means and standard deviations of all variables for each group in the pretest session and between-group comparisons

\begin{tabular}{|c|c|c|c|c|c|c|}
\hline \multirow{12}{*}{$\begin{array}{l}\text { Individual } \\
\text { characteristics }\end{array}$} & \multirow[b]{2}{*}{ Variables } & & \multirow{2}{*}{$\frac{\text { Control group }}{M(\mathrm{SD})}$} & \multirow{2}{*}{$\frac{\text { ToM group }}{M(\mathrm{SD})}$} & \multicolumn{2}{|l|}{ SIP group } \\
\hline & & & & & $M(\mathrm{SD})$ & $F$ \\
\hline & Sex (\% Male $)$ & & $56 \%$ & $38 \%$ & $53 \%$ & .62 \\
\hline & Chronological age & & $56.30(4.91)$ & $54.9(4.01)$ & $54.3(5.75)$ & .71 \\
\hline & Developmental age & Global & $62.60(13.26)$ & $57.9(9.70)$ & $62(10.79)$ & .79 \\
\hline & & Verbal & $61.80(12.21)$ & $57.1(8.28)$ & $59.9(10.84)$ & .81 \\
\hline & & Non-verbal & $64.80(22.04)$ & $59.6(20.94)$ & $66.2(15.57)$ & .49 \\
\hline & EBMCF & Conscientiousness & $5.73(1.99)$ & $6.07(2.14)$ & $6,53(1.67)$ & .40 \\
\hline & & Openness & $6.90(1.54)$ & $7.59(.836)$ & $7.93(.78)$ & 2.14 \\
\hline & & Agreeableness & $6.37(1.37)$ & $7.53(1.23)$ & $6.87(.98)$ & 2.61 \\
\hline & & Emotional stability & $5.85(1.47)$ & $6.24(1.65)$ & $6.14(1.24)$ & .18 \\
\hline & & Extraversion & $5.52(2.36)$ & $6.17(1.62)$ & $5.47(1.38)$ & .62 \\
\hline & CBCL & $\mathrm{EB}$ & $11.60(7.43)$ & $11.79(7.87)$ & $9.36(5.84)$ & .42 \\
\hline & & ER & $2.86(3.06)$ & $3.64(3.10)$ & $2.15(2.03)$ & .96 \\
\hline Social cognition & ToM & ToM emotions & $8.66(1.47)$ & $7.3(1.68)$ & $8.46(1.86)$ & 2.99 \\
\hline & & ToM beliefs & $4.20(.65)$ & $3.94(.89)$ & $3.47(1.34)$ & 2.15 \\
\hline & & ToMI & $15.33(1.76)$ & $14.05(2.26)$ & $16.25(1.58)$ & 2.86 \\
\hline & RES & & $60.63(14.08)$ & $57.44(17.90)$ & $56.4(11.55)$ & .35 \\
\hline Social & EASE & Non-ToM & $.85(.07)$ & $.83(.11)$ & $0.87(.12)$ & .59 \\
\hline adjustment & & ToM & $.73(.14)$ & $.70(.13)$ & $0.73(.15)$ & .41 \\
\hline & & Total & $.80(.10)$ & $.77(.11)$ & $.81(.13)$ & .39 \\
\hline
\end{tabular}


Note. $\mathrm{EBMCF}=$ Bipolar Rating Scales based on the Five Factor Model; $\mathrm{CBCL}=$ Child Behavior Checklist; EB $=$ Externalizing Behavior; ER $=$ Emotionally Reactive; ToM $=$ Theory of Mind; ToMI $=$ Theory of Mind Inventory; EASE = Social Adjustment Scales; RES = Social problem-solving task.

One-way ANOVAs revealed no significant difference between the three groups for sex, chronological age, developmental age, personality, social cognition or social adjustment. Consequently, the groups were equivalent in the pretest session.

Table 4 presents mean scores and standard deviations in the ToM and SIP tasks for the three groups in pretest and post-test.

Table 4. Means and standard deviations in pretest, post-test in ToM and SIP measures for each group and $t$-test for the pre/post-test difference

\begin{tabular}{lccccccccc}
\hline & \multicolumn{3}{c}{ Control group } & \multicolumn{3}{c}{ ToM group } & \multicolumn{3}{c}{ SIP group } \\
\cline { 2 - 10 } & Pretest & Post-test & $\Delta$ & Pretest & Post-test & $\triangle$ & Pretest & Post-test & $\Delta$ \\
\cline { 2 - 10 } & $M(\mathrm{SD})$ & $M(\mathrm{SD})$ & $t$ & $M(\mathrm{SD})$ & $M(\mathrm{SD})$ & $t$ & $M(\mathrm{SD})$ & $M(\mathrm{SD})$ & $t$ \\
\cline { 2 - 10 } ToM emotions & $8.66(1.47)$ & $8.03(1.64)$ & -.18 & $7.3(1.68)$ & $8.28(1.85)$ & $1.9^{*}$ & $8.46(1.86)$ & $8.6(1.58)$ & .39 \\
ToM beliefs & $4.19(.65)$ & $4.16(.83)$ & -.18 & $3.94(.89)$ & $4.25(.91)$ & $1.78^{*}$ & $3.47(1.34)$ & $4.17(.79)$ & $2.94^{\mathrm{a}}$ \\
RES & $60.63(14.1)$ & $64.88(15.54)$ & $1.75^{*}$ & $57.44(17.9)$ & $65.06(19.72)$ & $2.33^{* *}$ & $56.4(11.55)$ & $61.07(11.59)$ & $1.78^{*}$ \\
\hline Note. $=$ post-test - pretest difference. RES = Social problem-solving task; ToM = Theory of Mind. ${ }^{*} p \leq .10, * * p$ \\
$\leq .05,{ }^{a} p=.11$
\end{tabular}

For the pretest session, a one-way ANOVA showed no difference between groups for ToM emotions $(F(2)=$ 2.99), ToM beliefs $(F(2)=2.08)$, or RES $(F(2)=.35)$. For the post-test session, a one-way ANOVA showed no difference between groups for ToM emotions $(F(2)=.435)$, ToM beliefs $(F(2)=.058)$, or RES $(F(2)=.302)$.

\subsubsection{ToM Emotions}

A repeated measures ANOVA was conducted on the ToM emotions performance with pretest/post-test score as a within-group factor and as a between-groups factor. This analysis revealed no significant pre-post effect, $F(1)$ $=.455$, and a significant pre-post $\mathrm{X}$ group interaction, $F(2)=3.82, p<.05$. A one-way ANOVA with pre-post difference between groups revealed that the significant interaction between pre-post and groups was due to the fact that the improvement in the ToM group was significantly greater than in the control or SIP group. This pre-post comparison was significant in the ToM group but not in the two other groups.

\subsubsection{ToM Beliefs}

A repeated measures ANOVA was conducted on the ToM beliefs scores, showing a significant main pre-post effect, $F(1)=8.32, p<.01$, and a significant pre-post $\mathrm{X}$ group interaction, $F(2)=3.43, p<.05$. The significant main pre-post effect was further analyzed by one-tailed paired $t$-tests. The pre-post comparison was only significant in the ToM group, and there is a tendency for the SIP group $(p=.11)$, in contrast with the control group.

\subsubsection{RES}

A repeated measures ANOVA showed only a significant main pre-post effect, $F(1)=11.60, p=.001$. The pre-post X group interaction was not significant, $F(2)=.437$, ns. Post-hoc Bonferroni indicated that all groups showed a significant improvement on the RES task (see Table 4).

Although there is no significant difference between groups for the pre/post-test differences, the tendency showed that the ToM group (pre/post-test difference $=7.63)$ increased more than the control $($ pre/post-test difference $=$ 4.25) or SIP (pre/post-test difference $=4.67$ ) group for the RES task.

Finally, as shown in Table 4, in the control group, children had a tendency to achieve a lower score in post-test than in pretest for ToM beliefs and ToM emotions. They only improved their score in the RES. However, in both experimental groups, there are at least tendencies to improvement between pretest and post-test for each test (ToM emotions, ToM beliefs, and RES) in both groups.

\subsection{Links between ToM, SIP, and Individual Characteristics}

Figure 2 summarizes the results of significant correlational analyses obtained by applying Pearson's coefficient for all subjects combined in pretest. 


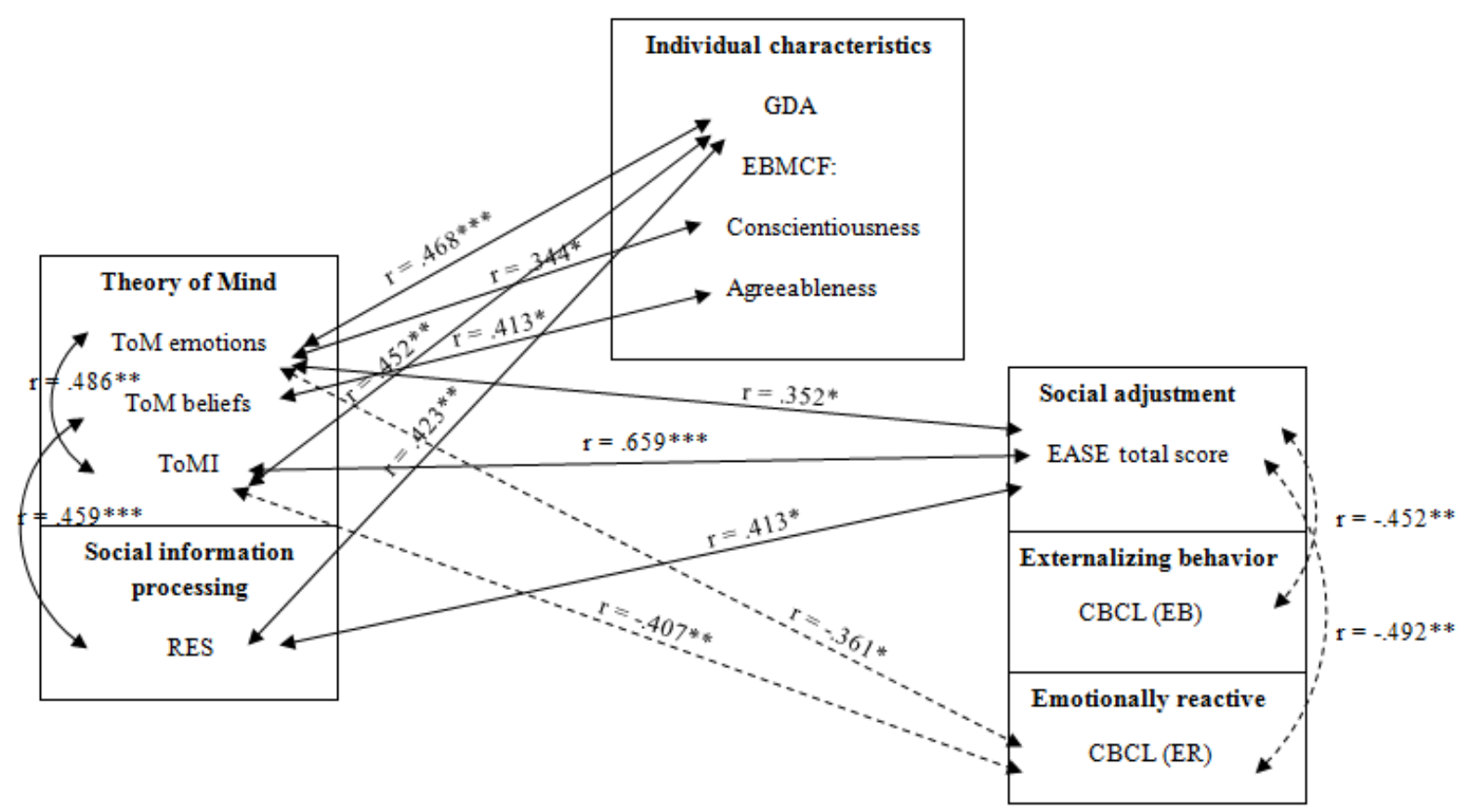

Figure 2. Summary of significant correlations between individual characteristics, socio-cognitive variables, social adjustment, and externalizing behavior for all subjects in pretest

Note. GDA = Global Developmental Age; EBMCF = Bipolar Rating Scales based on the Five Factor Model; $\mathrm{CBCL}=$ Child Behavior Checklist EB = Externalizing Behavior; ER = Emotionally Reactive; $\mathrm{ToM}=$ Theory of Mind; ToMI $=$ Theory of Mind Inventory; EASE $=$ Social Adjustment Scales; RES $=$ Social problem-solving task.

$$
\longleftrightarrow \begin{aligned}
& \longleftrightarrow \text { Positive links between variables; } \\
& \longleftrightarrow-\text { = Negative links between variables } \quad * p \leq .05, * * p \leq .01, * * * p \leq .001
\end{aligned}
$$

Significant correlations (from $p<.05$ to $p=.000$ ) are obtained between social cognition measures and individual characteristics, social cognition measures and social adjustment, and social cognition measures and ER, but also within the social cognition measures, between social adjustment and EB, and between social adjustment and ER. Positive significant correlations were obtained between global developmental age on the one hand and ToM emotions, ToMI, and RES on the other hand. Furthermore, ToM emotions were positively correlated with "conscientiousness', while ToM beliefs were positively correlated with "agreeableness." Positive significant correlations were also obtained between social adjustment on one hand and ToM emotions, ToMI, and RES on the other hand. Within the social cognition measures, ToM emotions and ToMI, as well as ToM beliefs and RES, were positively and significantly linked. Finally, ToM emotions and ToMI were correlated negatively and significantly to ER, and the social adjustment measure was negatively and significantly linked with EB and with ER. Moreover, the negative correlation obtained between ToM emotions and EB was nearly significant $(r=-.32$, $p=.054)$

\section{Discussion}

\subsection{Training Effects}

As predicted $(1 \mathrm{a}, 1 \mathrm{~b})$, this experiment demonstrated positive effects of one-shot training sessions in social cognition. We showed that training with feedback and explanations improved children's performances in the social cognition direct measures. Through quantitative and qualitative analysis, we found that ToM training led to a significant rise in ToM and SIP performances, while SIP training improved performance in RES and in ToM beliefs (tendency). The training not only improved performances in the trained skills, but also induced a transfer of learning to other social cognition tasks (prediction 1c). The transfer effect showed that training in one aspect of social cognition could influence children's understanding of other aspects of the mind. The mutual transfer effects between ToM and SIP tasks mean that, at least with those tasks, there is a causal link between ToM and SIP. As Kloo and Perner (2003) argued, the transfer effect on the socio-cognitive tasks indicates that children learned something that went beyond the immediate context of the task. 
The ToM training may have enabled children to interpret visual illustrations and to take the protagonist's point of view, which can be very useful for the SIP step. Conversely, the SIP training may have allowed participants to "feel what the protagonist might feel, how he might react...," which can be useful for understanding causes and consequences of emotions. Although the children in the SIP group were trained to generate an alternative appropriate response, they talked about the protagonist experiencing the emotions in order to justify their answers. Conversely, children in the ToM group probably used social problem-solving when they saw an extract from a cartoon about a child who was scared or sad, because the children had to talk about potential consequences of emotions and what the protagonist could do to stop that particular feeling.

The transfer effect may be explained by the fact that, in both groups, the experimenter used similar techniques of exchanges including inductive questions, explanation of expected responses and immediate differentiated feedback. Furthermore, children were placed in groups in order to create opportunities for "socio-cognitive conflicts" between children that could help bring about an evolution in their mental representations of social situations. In the case of wrong answers, each child was able to benefit from the help of another child or from corrections, feedback, or explanations of alternative or right answers.

One surprising result was that SIP training did not significantly enhance RES score compared with other groups. Contrary to expectation, the SIP group was not the one that displayed the greatest improvement in RES. Although there was no significant difference between groups for the pre/post-test differences, the tendency showed that the ToM group increased more than the control or SIP group for RES. One explanation for this may be the learning effect, because even the control group obtained significantly better scores in post-test than in pretest. However, the ToM group had a tendency to improve more than the other two groups. This could be explained by the fact that children seemed to enjoy the ToM training more than the SIP training - materials and exercises were probably more attractive and varied-which meant that they were more attentive and motivated. Another explanation could be that the SIP training always used critical or ambiguous social situations or provocation, while the RES assessment included both appropriate and inappropriate situations.

\subsection{Links between ToM, SIP and Individual Characteristics, Social Adjustment}

Preliminary social cognition measures correlated positively together. We found positive significant links between ToM emotions and ToMI (as found by Houssa et al., in press), and between ToM beliefs and RES. This result could be explained by the fact that the understanding of beliefs and social problem solving are probably more cognitive aspects of social cognition than ToM emotions. As Deneault and Ricard (2013) suggest, "emotion" is an affective mental state, while "belief" is more of a cognitive mental state.

Firstly, as expected (2a), correlations showed that social cognition aspects are positively linked to developmental age (except ToM beliefs). As several authors have shown (e.g., Schultz et al., 2010; Wellman \& Liu, 2004), this means that, as cognitive capacities (verbal and non-verbal intellectual level of efficiency) increase, children acquire abilities in social cognition.

Secondly, as expected (2b), some specific personality factors correlated positively with social cognition abilities. Conscientiousness was positively correlated to ToM emotions, while agreeableness was positively correlated to ToM beliefs. This means that the more children are perceived as having a high level of conscientiousness, the stronger their skills in ToM emotions. And the more children are perceived as having a high level of agreeableness, the higher their skills in ToM beliefs.

Thirdly, as predicted (2c), the social cognition measure (except ToM beliefs) correlated positively with social adjustment. The children who have better abilities in social cognition are better adjusted socially (Denham \& Burton, 2003; Houssa et al., submitted; Nader-Grosbois, Houssa \& Mazzone, 2013).

Fourthly, we hypothesized (2d) that social cognition measures would be negatively correlated to externalizing behavior, but the negative correlations obtained between ToM emotions and EB were not quite significant. As our sample was composed of normally developing pre-schoolers, without behavior problems, this low correlation may be due to the variance in EB score. The negative correlation may be significant with children who have more variance in their externalizing behavior score (e.g., Nader-Grosbois et al., 2013).

Fifthly, as expected, we found a significant negative correlation between social cognition or social adjustment measures, and social maladjustment measures. This means that if children were perceived as socially well-adjusted, they displayed few externalizing behavior problems, and conversely, if children were perceived as having a lot of externalizing behavior problems, they were also perceived as more socially maladjusted (Ladd \& Troop-Gordon, 2003; Nader-Grosbois \& Fiasse, 2011b, p.286). Furthermore, we expected (2e) negative links between ToM emotions, ToMI, and emotional reactivity. This means that if children had good scores in ToM, or 
were perceived by their parents as having good abilities in ToM, they were perceived as having a low level of emotional reactivity (or vice versa). As regards the link between social adjustment and emotional reactivity, this means that the more the child was perceived as being socially well adjusted, the more he/she was perceived as having low emotional reactivity (or vice versa).

It might be interesting to test these training sessions with atypical children (e.g., children with or at risk of developing externalizing problems) in order to vary the score for social (mal)adjustment. Furthermore, it could be relevant to test this kind of training via medium-term training (for instance, 15 sessions over 2 months).

\section{Implications for Research and Intervention}

In summary, this battery of pretests and post-tests does differentiate between socio-cognitive profiles and could be useful for detecting weaknesses in pre-schoolers in order to better understand social (mal) adjustment, as this is a critical developmental period just before the start of primary school, where the child will create his or her social network of peers. Results showed positive quantitative and qualitative effects of both types of short-term training and confirmed that the two training procedures are efficient. Future studies should determine whether these improvements are observed in atypical populations. For instance, these procedures could help EB children to increase their socio-cognitive skills and, consequently, to decrease their EB and their social maladjustment.

Early detection of socio-cognitive difficulties could allow intervention before the emergence of lasting difficulties in childhood and help to limit the child's disabilities (primary prevention). As Denham, Bassett, Mincic, Kalb, Way, Wyatt, and Segal (2012) have shown, children who have lower sad-prosocial and higher angry-aggressive choices to hypothetical peer provocation also have weaker skills in social problem-solving (children in the "social-emotional learning risk group"). According to these authors, pre-schoolers' programming should take social-emotional learning into account, because the "social-emotional learning risk group" is characterized by difficulty in understanding and identifying emotions and an angry-aggressive pattern of social problem-solving. Training for at-risk pre-schoolers is critical, as it lays the foundations for later development and behavior concerning their social environment (Webster-Stratton et al., 2011).

This study could help teachers and parents by providing a basis for early training plans, as these types of training can ensure better social adjustment and integration.

\section{References}

Achenbach, T. M., \& Rescorla, L. A. (2000). Manual for the ASEBA Preschool Forms \& Profiles. Burlington, VT: University of Vermont, Research Center for Children, Youth, \& Families.

Amsterlaw, J., \& Wellman, H.M. (2006). Theories of mind in transition: A microgenetic study of the development of false belief understanding. Journal of Cognition and Development, 7, 139-172. http://dx.doi.org/10.1207/s15327647jcd0702_1

Appleton, M., \& Reddy, V. (1996). Teaching three year-olds to pass false belief tests: A conversational approach. Social Development, 5, 275-291. http://dx.doi.org/10.1111/j.1467-9507.1996.tb00086.x

Barisnikov, K., Van der Linden, M., \& Hippolyte, L. (2004). Tâche de résolution sociale. Unpublished manual. Genève

Begeer, S., Gevers, C., Clifford, P., Verhoeve, M., Kat, K., Hoddenbach, E., \& Boer, F. (2011). Journal of Autism and Developmental Disorders, 41, 997-1006. http://dx.doi.org/10.1007/s10803-010-1121-9

Bhavnagri, N. P., \& Samuels, B. G. (1996). Children's literature and activities promoting social cognition of peer relationships in preschoolers. Early Childhood Research Quarterly, 11, $307-331$. http://dx.doi.org/10.1016/S0885-2006(96)90010-1

Blair, R.J.R. \& Coles, M. (2003). Expression recognition and behavioral problems of early adolescence. Cognitive Development, 15(4), 421-434. http://dx.doi.org/10.1016/S0885-2014(01)00039-9

Clements, W. A., Rustin, C. L., \& McCallum, S. (2000). Promoting the transition from implicit to explicit understanding: A training study of false belief. Developmental Science, 3, 81-92. http://dx.doi.org/10.1111/1467-7687.00102

Comte-Gervais, I., Giron, A., Soares-Boucaud, I., \& Poussin, G. (2008). Evaluation de l'intelligence sociale chez l'enfant. L'information psychiatrique, 84, 667-673.

Crick, N. R., \& Dodge, K. A. (1994). A review and reformulation of social information processing mechanisms in children's social adjustment. Psychological Bulletin, 115, 74-101. http://dx.doi.org/10.1037/0033-2909.115.1.74 
Deneault, J., \& Ricard, M. (2013). Are emotion and mind understanding differently linked to young children's social adjustment? Relationships between behavioral consequences of emotions, false belief, and SCBE. The journal of Genetic Psychology, 174(1), 88-116. http://dx.doi.org/10.1080/00221325.2011.642028

Denham, S. A., Bassett, H., Mincic, M., Kalb, S., Way, E., Wyatt, T., \& Segal, Y. (2012). Social-emotional learning profiles of preschoolers' early school success: A person-centered approach. Learning and individual differences, 22, 178-189. http://dx.doi.org/10.1016/j.lindif.2011.05.001

Denham, S. A., Blair, K. A., DeMulder, E., Levitas, J., Sawyer, K., Auerbach-Major, S., \& Queenan, P. (2003). Preschool emotional competence: Pathway to social competence? Child Development, 74(1), 238-256. http://dx.doi.org/10.1111/1467-8624.00533

Denham, S. A., \& Burton, R. (2003). Social and emotional prevention and intervention programming for preschoolers. New York: Kluwer-Plenum. http://dx.doi.org/10.1007/978-1-4615-0055-1

Denham, S. A., Zinsser, K., \& Bailey, C. S. (2011). Emotional intelligence in the first five years of life. Lewis, M. topic ed. In: Trembay RE, Boivin, M., Peters RDeV, eds. Encyclopedia on Early Childhood Development (online). Montreal, Quebec: Centre of Excellence for Early Childhood Development and Strategic Knowledge Cluster on Early Child Development, 1-7.

Dodge, K. A., \& Crick, N. R. (1990). Social information-processing bases of aggressive behavior in children. Personality and Social Psychology Bulletin, 16, 8-22. http://dx.doi.org/10.1177/0146167290161002

Dodge, K. A. \& Pettit, G. S. (2003). A biopsychosocial model of the development of chronic conduct problems in adolescence. Developmental Psychology, 39(2), 349-371. http://dx.doi.org/10.1037/0012-1649.39.2.349

Fahie, C. M., \& Symons, D. K. (2003). Executive functioning and theory of mind in children clinically referred for attention and behavior problems. Applied Developmental Psychology, 24, 51-73. http://dx.doi.org/10.1016/S0193-3973

Feng, H., Lo, Y., \& Tsai, S. (2008). The effects of theory of mind and social skills training on the social competence in a sixth-grade student with autism. Journal of Positive Behavior Interventions, 10(4), 228-242. http://dx.doi.org/10.1177/1098300708319906

Flavell, J. H. (1986). The development of children's knowledge about the appearance-reality distinction. American Psychologist, 41(4), 418-425. http://dx.doi.org/10.1037/0003-066X.41.4.418

Flavell, J. H. (1999). Cognitive development: Children's knowledge about the mind. Annual Review of Psychology, 50, 21-45. http://dx.doi.org/10.1146/annurev.psych.50.1.21

Flavell, J. H., Everett, B. A., Croft, K., \& Flavell, E. R. (1981). Young children's knowledge about visual perception: Further evidence for the level 1-level 2 distinctions. Developmental Psychology, 17(1), 99-103. http://dx.doi.org/10.1037/0012-1649.17.1.99

Fontaine, R. G., \& Dodge, K. A. (2009). Social information processing and aggressive behavior: A transactional perspective. In A. J. Sameroff (Ed.), The transactional model of development: How children and contexts shape each other (pp. 117-135). Washington, DC: American Psychological Association. http://dx.doi.org/10.1037/11877-007

Gevers, C., Clifford, P., Mager, M., \& Boer, F. (2006). Brief report: A theory-of-mind-based social-cognition training program for school-aged children with pervasive developmental disorders: An open study of its effectiveness. Journal of Autism and Developmental Disorders, 36(4), 567-571. http://dx.doi.org/10.1007/s10803-006-0095-0

Hadwin, J., Baron-Cohen, S., Howlin, P., \& Hill, K. (1996). Can a theory of mind be taught to children with autism? Development and Psychopathology, 8, 345-365. http://dx.doi.org/10.1017/S0954579400007136

Hippolyte, L., Iglesias, K., Van der Linden, M., \& Barisnikov, K. (2010). Social reasoning skills in adults with Down syndrome: the role of language, executive functions and socio-emotional behavior. Journal of Intellectual Disability Research, 54(8), 714-726. http://dx.doi.org/10.1111/j.1365-2788.2010.01299.x

Houssa, M., Mazzone, S., \& Nader-Grosbois, N. (in press). Validation d'une version francophone de l'Inventaire de la Théorie de l'Esprit. European Review of Applied Psychology.

Howlin, P., Baron-Cohen, S., \& Hadwin, J. (2011). Apprendre aux enfants autistes à comprendre la pensée des autres.Bruxelles: De Boeck.

Hughes, C., Dunn, J., \& White, A. (1998). Trick or treat? Uneven understanding of mind and emotion and 
executive dysfunction in "Hard-to-manage" preschoolers. Journal of Child Psychology and Psychiatry, 39(7), 981-994. http://dx.doi.org/10.1111/1469-7610.00401

Hughes, C., Soares-Boucaud, I., Hochman, J., \& Frith, U. (1997). Social behavior in pervasive developmental disorders: effects of informant, group and "theory of mind". European Child and Adolescent Psychiatry, 6, 191-198.

Hutchins, T. L., Prelock, P. A., \& Bonazinga, L. A. (2012). Psychometric evaluation of the theory of mind inventory (ToMI): A study of typically developing children and children with autism spectrum disorder. Journal of autism and developmental disorders, 42, 327-341. http://dx.doi.org/10.1007/s10803-011-1244-7

Juarez Monfort, I., Juarez Sanchez, A., \& Monfort, M. (2009). Mental Simil. Editions Entha.

Kloo, D., \& Perner, J. (2003). Training transfer between card sorting and false belief understanding: Helping children apply conflicting descriptions. Child Development, 74, 1823-1839. http://dx.doi.org/10.1046/j.1467-8624.2003.00640.x

Ladd, G. D. \& Troop-Gordon, W. (2003). The role of chronic peer difficulties in the development of children's psychological adjustment problems. Child Development, 74(5), 1344-1367. http://dx.doi.org/10.1111/1467-8624.00611

Marsh, A. A., \& Blair, R. J. R. (2008). Deficits in facial affect recognition among antisocial populations: A meta-analysis. Neuroscience and Biobehavioral Reviews, 32, 454-465. http://dx.doi.org/10.1016/j.neubiorev.2007.08.003

Mize, J., \& Pettit, G. S. (2008). Social information-processing and the development of conduct problems in children and adolescents: Looking beneath the surface. In C. Sharp, P. Fonagy, \& I. Goodyer (Eds.), Social cognition and developmental psychopathology (pp. 141-174). New York: Oxford University Press. http://dx.doi.org/10.1093/med/9780198569183.003.0006

Melot, A. M., \& Angeard, N. (2003). Theory of Mind: Is training contagious? Developmental Science, 6, 178. http://dx.doi.org/10.1111/1467-7687.00269

Nader-Grosbois, N., Houssa, M., \& Mazzone, S. (2013). How could theory of mind contribute to the differentiation of social adjustment profiles of children with externalizing behavior disorders and children with intellectual disabilities? Research in Developmental Disabilities, 34, 2642-2660. http://dx.doi.org/10.1016/j.ridd.2013.05.010

Nader-Grosbois, N., \& Thirion-Marissiaux, A. F. (2008). Manuel des épreuves d'évaluation de la théorie de l'esprit relatives aux émotions et aux croyances. Université catholique de Louvain, Louvain-la-Neuve.

Nader-Grosbois, N., \& Thirion-Marissiaux, A. F. (2011a). Evaluer la compréhension des états mentaux «émotions » et «croyances». In N. Nader-Grosbois Théorie de l'esprit : Entre cognition, émotion et adaptation sociale chez des personnes typiques et atypiques (pp. 95-124). Bruxelles: De Boeck.

Nader-Grosbois, N., \& Thirion-Marissiaux, A. F. (2011b). Théorie de l'esprit chez des enfants avec troubles du comportement et caractéristiques développementales, cognitives, affectives et en adaptation sociale. In N. Nader-Grosbois Théorie de l'esprit : Entre cognition, émotion et adaptation sociale chez des personnes typiques et atypiques (pp. 283-299). Bruxelles: De Boeck.

Orobio de Castro, B., Veerman, J. W., Koops, W., Bosch, J. D., \& Monshouwer, H. J. (2002). Hostile attribution of intent and aggressive behavior: A meta-analysis. Child Development, 73, 916-934. http://dx.doi.org/10.1111/1467-8624.00447

Oswald, D. P., \& Ollendick, T. H. (1989). Role taking and social competence in autism and mental retardation. Journal of autism and developmental disorders, 19(1), 119-127. doi.org/10.1007/BF02212723

Ozonoff, S., \& Miller, J. (1995). Teaching theory of mind: A new approach to social skills training for individuals with autism. Journal of Autism and Developmental Disorders, 25(4),415-433. http://dx.doi.org/10.1007/BF02179376

Parsons, S., \& Mitchell, P. (1999). What children with autism understand about thoughts and thought bubbles. Autism, 3, 17-38. doi.org/10.1177/1362361399003001003

Pears, K. C., Fisher, P. A., \& Bronz, K. D. (2007). An intervention to promote social emotional school readiness in foster children: Preliminary outcomes from a pilot study. School Psychological Review, 36(4), 665-673. 
Perner, J., Leekam, H., \& Wimmer, H. (1987). Three-year-olds' difficulty with false belief: The case for a conceptual deficit. British Journal of Developmental Psychology, 5, 125-137. http://dx.doi.org/10.1111/j.2044-835X.1987.tb01048.x

Perron-Borelli, M. (1996). Echelles Différentielles d'Efficiences Intellectuelles. Forme révisée (EDEI-R). Paris: Editions et Applications Psychologiques.

Pettit, G. S., Dodge, K. A., \& Brown, M. M. (1988). Early family experience, social problem solving patterns, and children's social competence. Child Development, 59, 107-120. http://dx.doi.org/10.2307/1130393

Roskam, I., De Maere-Gaudissart, A. \& Vandenplas-Holper, C. (2000). Mise au point d'un instrument d'évaluation de la personnalité des enfants à partir du Modèle à Cinq Facteurs. L'Orientation Scolaire et Professionnelle, 29(4), 661-672.

Runions, K. C., \& Keating, D. P. (2007). Young children's Social Information Processing: Family antecedents

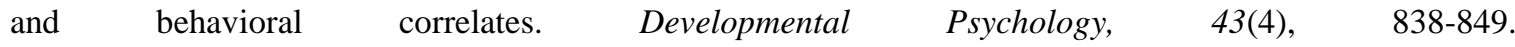
http://dx.doi.org/10.1037/0012-1649.43.4.838

Silver, M., \& Oakes, P. (2001). Evaluation of a new computer intervention to teach people with autism or Asperger syndrome to recognize and predict emotions in others. Autism, 5(3), 299-316. http://dx.doi.org/10.1177/1362361301005003007

Schultz, D., Ambike, A., Logie, S. K., Bohner, K. E., Stapleton, L. M., VanderWalde, H., Min, C. B., \& Jetkowski, J. A. (2010). Assessment of Social Information Processing in Early Childhood: Development and Initial Validation of the Schultz Test of Emotion Processing - Preliminary version. Journal of Abnormal Child Psychology, 38, 601-613. http://dx.doi.org/10.1007/s10802-010-9390-5

Shure, M. B., \& Spivack, G. (1982). Interpersonal problem-solving in young children: A cognitive approach to prevention. American Journal of Community Psychology, 10(3), 341-356. http://dx.doi.org/10.1007/BF00896500

Swettenham, J. S. (1996). Can children with autism be taught to understand false belief using computers? Journal of Child Psychology and Psychiatry, 37(2), 157-165. http://dx.doi.org/10.1111/j.1469-7610.1996.tb01387.x

Walker, S. (2005). Gender differences in the relationship between young children's peer-related social competence and individual differences in theory of mind. The Journal of Genetic Psychology, 166(3), 297-312. http://dx.doi.org/10.3200/GNTP.166.3.297-312

Webster-Stratton, C. (2000). The Incredible Years Training Series. Juvenile justice bulletin. http://dx.doi.org/10.3200/GNTP.166.3.297-312

Webster-Stratton, C., Reid, J., \& Beauchaine, T. (2011). Combining parent and child training for young children with ADHD. Journal of Clinical Child \& Adolescent Psychology, 40(2), 191-203. http://dx.doi.org/10.1080/15374416.2011.546044

Wellman, H. M. (1991). From desires to beliefs: acquisition of a theory of mind. In A. Whiten (Ed.), Natural theories of mind (pp. 19-38). Cambridge, MA: Basil Blackwell.

Yeates, K. O., Dennis, M., Rubin, K. H., Taylor, H. G., Bigler, E. D., Gerhardt, C. A., \& Vannatta, K. (2007). Social outcomes in childhood brain disorder: A heuristic integration of social neuroscience and $\begin{array}{lllll}\text { developmental psychology. } & \text { Psychological }\end{array}$ http://dx.doi.org/10.1037/0033-2909.133.3.535

Wimmer, H., \& Perner, J. (1983). Beliefs about beliefs: Representation and constraining function of wrong beliefs in young children's understanding of deception. Cognition, 13, 103-128. http://dx.doi.org/10.1016/0010-0277(83)90004-5

Ziv, Y., \& Sorongon, A. (2011). Social information processing in preschool children: Relations to sociodemographic risk and problem behavior. Journal of Experimental Child Psychology, 109, 412-429. http://dx.doi.org/10.1016/j.jecp.2011.02.009 
Appendix A. ToM training

\begin{tabular}{|c|c|c|c|c|c|}
\hline ToM Training & Resources & & $\begin{array}{l}\text { Functions: mental state } \\
\text { or social situation }\end{array}$ & Description & $\begin{array}{l}\text { Timing } \\
(\mathrm{sec} .)\end{array}$ \\
\hline \multirow{10}{*}{$\begin{array}{l}\text { Howlin et al. } \\
\text { (2011) }\end{array}$} & \multirow{10}{*}{$\begin{array}{l}\text { Computerized } \\
\text { picture stories }\end{array}$} & \multirow{4}{*}{$\begin{array}{l}\text { Situation-based } \\
\text { emotions }\end{array}$} & Joy & Alan is given an ice cream & 120 \\
\hline & & & Anger & Julie breaks Kevin's car & 120 \\
\hline & & & Fear & Suzanne is scared of the spider & 120 \\
\hline & & & Sadness & Sylvette's dad is leaving & 120 \\
\hline & & \multirow{2}{*}{$\begin{array}{l}\text { Desire-based } \\
\text { emotions }\end{array}$} & Joy & Mila wants to ride a horse & 150 \\
\hline & & & Sadness & $\begin{array}{l}\text { Xavier wants an orange juice but is } \\
\text { given a hot chocolate }\end{array}$ & 150 \\
\hline & & \multirow[t]{4}{*}{$\begin{array}{l}\text { Belief-based } \\
\text { emotions }\end{array}$} & $\begin{array}{l}\text { True belief and } \\
\text { fulfilled desire }\end{array}$ & $\begin{array}{l}\text { Betty wants and believes she will be } \\
\text { given a teddy bear, and is given one }\end{array}$ & 180 \\
\hline & & & $\begin{array}{l}\text { True belief and } \\
\text { unfulfilled desire }\end{array}$ & $\begin{array}{l}\text { At the circus, Thomas wants to see } \\
\text { lions but believes that he will see } \\
\text { clowns, and does see clowns }\end{array}$ & 180 \\
\hline & & & $\begin{array}{l}\text { False belief and } \\
\text { fulfilled desire }\end{array}$ & $\begin{array}{l}\text { Claire wants to see pigs but believes } \\
\text { she will see sheep; she sees pigs }\end{array}$ & 180 \\
\hline & & & $\begin{array}{l}\text { False belief and } \\
\text { unfulfilled desire }\end{array}$ & $\begin{array}{l}\text { Jean wants his grandfather to stay and } \\
\text { believes that he will, but he leaves }\end{array}$ & 180 \\
\hline \multirow[t]{8}{*}{ Cartoons } & \multirow[t]{8}{*}{ Cartoons } & \multirow[t]{4}{*}{ Emotions } & Joy & A little girl is given a gift & 32 \\
\hline & & & Anger & $\begin{array}{l}\text { At dinner, a mother is angry with her } \\
\text { children because they are fighting }\end{array}$ & 20 \\
\hline & & & Sadness & $\begin{array}{l}\text { Little Red Riding Hood's grandmother } \\
\text { has to leave }\end{array}$ & 28 \\
\hline & & & Fear & $\begin{array}{l}\text { A girl is looking for Mowgli in the } \\
\text { jungle at night, and she is afraid of an } \\
\text { owl }\end{array}$ & 32 \\
\hline & & \multirow[t]{4}{*}{ Beliefs } & Appearance-Reality & $\begin{array}{l}\text { Snow White mistakes pieces of wood } \\
\text { for crocodiles }\end{array}$ & 40 \\
\hline & & & False belief & $\begin{array}{l}\text { The queen looks like an old woman } \\
\text { and poisons an apple intended for } \\
\text { Snow White }\end{array}$ & 105 \\
\hline & & & & $\begin{array}{l}\text { Little Red Riding Hood goes to see } \\
\text { her grandmother, but it is the big bad } \\
\text { wolf in disguise }\end{array}$ & 26 \\
\hline & & & Location change & $\begin{array}{l}\text { A girl is drawing and leaves for a } \\
\text { while. Another girl comes along and } \\
\text { changes the location of the pen }\end{array}$ & 28 \\
\hline \multirow{4}{*}{$\begin{array}{l}\text { Mental Simil } \\
\text { (Juarez-Monfort } \\
\text { et al., 2009) }\end{array}$} & \multirow[t]{4}{*}{$\begin{array}{l}\text { Story } \\
\text { pictures }\end{array}$} & \multirow{4}{*}{\multicolumn{2}{|c|}{ False belief }} & $\begin{array}{l}\text { A boy pretends that he is injured. He } \\
\text { has a bandage with ketchup }\end{array}$ & 180 \\
\hline & & & & $\begin{array}{l}\text { A boy is disguised as a shark and } \\
\text { frightens some friends }\end{array}$ & 180 \\
\hline & & & & $\begin{array}{l}\text { A dad believes that his baby has } \\
\text { ruined the picnic, but it was due to } \\
\text { someone else's ball }\end{array}$ & 180 \\
\hline & & & & $\begin{array}{l}\text { The cat has broken the candy bowl } \\
\text { and the mother believes her daughter } \\
\text { has done it }\end{array}$ & 180 \\
\hline
\end{tabular}


Appendix B. SIP training

\begin{tabular}{|c|c|c|c|c|c|}
\hline $\begin{array}{l}\text { SIP } \\
\text { Training }\end{array}$ & Resources & \multicolumn{2}{|c|}{$\begin{array}{l}\text { Functions: Mental state or } \\
\text { social situation }\end{array}$} & Description & $\begin{array}{l}\text { Timing } \\
(\mathrm{sec})\end{array}$ \\
\hline \multirow{9}{*}{$\begin{array}{l}\text { STEP-P } \\
\text { (Schultz } \\
\text { et al., } \\
\text { 2010) }\end{array}$} & \multirow{9}{*}{$\begin{array}{l}\text { Video } \\
\text { illustrating } \\
\text { social } \\
\text { situations }\end{array}$} & \multirow[t]{3}{*}{ Emotion } & \multirow[t]{3}{*}{ Anger/sadness } & Two boys are playing; one of them cheats & 20 \\
\hline & & & & A girl is sitting at the table with arms crossed & 25 \\
\hline & & & & A girl says to her friend: "Leave me alone" & 22 \\
\hline & & \multirow[t]{3}{*}{$\begin{array}{l}\text { Goal } \\
\text { acquisition }\end{array}$} & \multirow[t]{3}{*}{$\begin{array}{l}\text { Aggressive/ } \\
\text { cooperative }\end{array}$} & $\begin{array}{l}\text { After asking for a toy, a boy takes one out of another boy's } \\
\text { hands }\end{array}$ & 25 \\
\hline & & & & $\begin{array}{l}\text { A girl asks her friend to help but she says "no." She } \\
\text { threatens her }\end{array}$ & 25 \\
\hline & & & & $\begin{array}{l}\text { A boy asks to play with a puzzle. His friend says "no" and } \\
\text { the boy threatens him }\end{array}$ & 29 \\
\hline & & \multirow[t]{3}{*}{ Provocation } & Physical & Two girls are playing with a ball; the ball hits another girl & 30 \\
\hline & & & Physical & A boy is walking along and breaks the towel of another boy & 15 \\
\hline & & & $\begin{array}{l}\text { Social } \\
\text { exclusion }\end{array}$ & A girl refuses to let another girl sit down & 22 \\
\hline \multirow{3}{*}{$\begin{array}{l}\text { SIP-I } \\
\text { (Ziv et } \\
\text { al., } \\
2011)\end{array}$} & \multirow{3}{*}{$\begin{array}{l}\text { Story } \\
\text { illustrating } \\
\text { social } \\
\text { situations } \\
\text { by } \\
\text { pictures } \\
\text { with bears }\end{array}$} & \multirow{3}{*}{\multicolumn{2}{|c|}{$\begin{array}{l}\text { Critical social situations } \\
\text { involving potential hostile } \\
\text { attribution bias }\end{array}$}} & $\begin{array}{l}\text { Mickaël is watching TV and another boy comes along and } \\
\text { takes the remote }\end{array}$ & 300 \\
\hline & & & & $\begin{array}{l}\text { Mickaël asks some children if he can play with them but } \\
\text { they do not answer }\end{array}$ & 300 \\
\hline & & & & $\begin{array}{l}\text { A child accidentally knocks over Mickaël's glass and spills } \\
\text { his drink }\end{array}$ & 300 \\
\hline
\end{tabular}

\section{(cc) $\mathrm{BY}$}

This work is licensed under a Creative Commons Attribution 3.0 License. 